\title{
The Correlation between Community Care Centres and the Social Interaction among the Elderly
}

\author{
Miao-Fen Lin ${ }^{1}$, Yi-Wen Chiu ${ }^{2 *}$ and Chi-Hsuan Lung ${ }^{3}$ \\ ${ }^{1}$ Department of Nursing, Chung Hwa University of Medical Technology, Taiwan, R.O.C. \\ ${ }^{2}$ Department of Nursing, Chung Shan Medical University, Taichung, Taiwan, R.O.C. \\ ${ }^{3}$ Department of Senior Citizen Services, National Tainan Junior College of Nursing, Taiwan, R.O.C.
}

\begin{abstract}
"Aging in place" is a common strategy to cope with the problem of aging and advocate the promotion of social interaction among the aged people. Taiwan is also looking forward to the active aging of the elderly through the participation of community activities. The purpose of this study is to explore the impact of participation in community care centres on social interactions among the elderly. This study used a cross-sectional questionnaire to collect data. A total of 92 valid samples were analysed with SPSS 22.0. Research has shown that social interactions are significantly better for older people who have jobs, who participate in health promotion activities, and who participate more frequently and for longer periods of time. Community based care centres can promote better social interactions for the elderly. We should properly plan and design a variety of courses to enable the elderly to continue to actively participate in society.
\end{abstract}

KEYWORDS: Community based care center; Elderly; Social interaction; Aging in place

\section{INTRODUCTION}

Aging, accompanied by the decline of physical functions, the occurrence of diseases and changes in social role, social status or lifestyles, may reduce the opportunity for social interaction, which would further affect the self-identity of the elderly, resulting in negative and pessimistic emotions, making it easy for the elderly to feel lonely and lose vitality in life $\mathrm{Wu}$ [1]; $\mathrm{Wu}$ [2].

Rowe [3] pointed out in the theory of successful aging that active participation in activities could facilitate social interaction, and in the interaction process, support from others can be obtained through exchanges, which would be beneficial for health. World Health Organization (WHO) even positively presented Active Aging in 2002, advocating "the process of doing the best to improve health, social participation and safety to improve the quality of life as we age" to construct an age-friendly living environment based on this concept WHO [4].
$\mathrm{Wu}$ [1]; $\mathrm{Wu}$ [2] pointed out in the studies that if the elderly could continue to participate in social activities, interact with people, and maintain their social roles, they could achieve self-affirmation and satisfaction of positive emotions to maintain the abilities of independent living, which could help them with the adaptation to their later life and thereby prevent and delay the degradation of physical and mental functions. Lewis et al. [5] indicated in the study that the elderly could acquire health resources through social interactions with friends, family members, community and local organizations that would further change their health behaviour. Pieter-Paul [6] pointed out that those with active participation in activities with friends and family members and those with social networks were positively correlated with their self-rated health. Steptoe [7] conducted a longitudinal study on the correlation between social contacts and the health of the elderly, and the results suggested that social isolation and loneliness were significantly correlated with mortality. Hsieh [8] also found in the study that

Quick Response Code:

Address for correspondence: Yi-Wen Chiu, Department of Nursing, Chung Shan Medical University, Taiwan, R.O.C.

Received: September 15, 2020 Published: October 12, 2020

How to cite this article: Miao-Fen L, Yi-Wen C, Chi-Hsuan L. The Correlation between Community Care Centres and the Social Interaction among the Elderly. 2020 - 2(5) OAJBS. ID.000226. DOI: $10.38125 / \mathrm{OAJBS} .000226$ 
when the retired seniors participated in meaningful activities more often after retirement and maintained their consistent lifestyle, their overall quality of life would be better. It can be observed that when the elderly maintains certain activities and interpersonal relationships, it is easier to promote their physiological functions.

Due to the rising aging index in Taiwan, the population dependency structure is mainly focused on old-age dependency, coupled with the concept of "a falling leaf should return to the roots" in traditional Chinese culture, people hope to settle down in their familiar life circle in their later life due to the connection with the land. Therefore, aging in place has been the long-term goal for the aging policy in Taiwan. As a result, the government authority has actively promoted the establishment of Community Care Centres to advocate the maintenance or active development of the social role of the elderly for them to adapt to changes in the environment. The community care centres can provide a convenient and diverse field for activities, serving as a link between the elderly and their family members as well as the neighbours. At the same time, through the strength of associations and volunteers, primary preventive care services can be provided to the elderly in good health and subhealth in the communities, such as home visits, friendly phone calls, counselling and referrals, health promotion and food catering. Through the provision of various services and arrangement of activities of the care centres, the social interaction of the elderly can be increased, strengthening their social participation and sense of belonging in the community to activate their elderly life and prevent and delay disability Social and Family Affairs Administration Ministry of Health and Welfare [9].

Lee [10] analysed the elders receiving the services of the community care centres and found considerable effects on the improvement and maintenance of their physiological and mental health after their participation in the services provided. Ko [11] also had the same findings in the study that when the elderly made use of the services provided by the community care centres, such as the health promotion activities, their physical and mental health as well as their perceived changes of their social functions could be significantly improved. Cheng [12] also proved this argument in their survey on the effectiveness of the community care centres among the elderly users in Taiwan and concluded that the users' living space was expanded, their frequency of interaction with friends and relatives was also increased, and more than $80 \%$ of the users had good physical and mental health.

The government has set up community care centres to construct a social network for the elderly through the provision of official care services. However, there is very little research on the influence of the service contents provided on the family and neighbour relationships. Therefore, the researcher aimed at probing into the possibility of shaping the social support function of the community network with the elders' participation in the activities of the community care centres based on the interpersonal relationship as the basis of interaction process.

\section{MATERIALS AND METHODS}

Cross-sectional questionnaires were used in this study during December 10, 2018 and January 4, 2019 for data collection. Purposive sampling was applied to recruit the elders in the community care centres in Sinshih District in Tainan City, and the inclusion criteria included 1) those aged 65 years and above; 2) those with clear expression ability; 3 ) those who could or were willing to fill out the questionnaire. Power analysis with G Power 3.1 was conducted for sample size calculation, and the medium effect size $=0.3$ Kraemer [13], significant level $\alpha=0.05$, the statistical power $=0.8$ as the set parameters. After calculation by the software, the required sample size was 84 . A total number of 106 participants were recruited, with a loss of 14 participants, so the effective sample size of this study was 92 .

The community care centres are open on weekdays, and the service items formally provided are home visits, friendly phone calls, food catering and health promotion activities, and the detailed service items may vary depending on different centres. In terms of food catering service, it is averagely provided once to twice a week, but some centres only provide food delivery while some provide both food delivery and group meals; health promotion activities are provided twice a week. In addition, the centres also provide informal library services, including blood pressure measurement, fitness equipment, newspapers and magazines, karaoke, and tea area, and the space of the centres also serves as a recreational and relaxing place for the public.

The research tool of this study was a structured questionnaire whose content included two parts: basic information and social interaction. Basic information contained demographic characteristics and activity participation. The social interaction scale comprehensively referred to those from scholars such as Chen [14]; Lin [15]; Chen [16]; Ko [11] and was divided into emotional, instrumental, informational and interactive aspects. In addition, considering that the government has set up community care centres to provide the elderly a field for leisure and recreation in the community to enhance the interaction between the elderly and their neighbours, the researcher revised the scales after referring to literature and focused on the family relationship and neighbour relationship under the four aspects of the scale for discussion. A 5-point Likert Scale was adopted for scoring, and the scores ranged from 5 to 1 for "Strongly Agree", "Agree", "Neutral", "Disagree" and "Strongly Disagree" respectively. After summing up the points of every aspect, the higher the score, the better the social interaction. On the contrary, the lower the score, the worse the social interaction. The scale used expert content validity testing, and the overall scale reliability Cronbachs' $\alpha$ reached 960.

After collecting, coding and documenting the questionnaire data, SPSS Statistics 22.0 was used for statistical analysis with $\alpha=.05$ as the basis for significant level, and descriptive and inferential statistical analysis were carried out according to the research questions.

\section{RESULTS}

It was known from sample analysis (Table 1) that females accounted for $56.5 \%$ of the participants; most of the participants were aged between 65-74 accounting for 54.3\%; the level of education was generally lower, and $70.6 \%$ received primary school or lower education; in terms of marital status, the majority had spouses, accounting for $54.3 \%$; $65.2 \%$ lived with their family; $97.8 \%$ had general folk beliefs; in terms of diseases, most respondents only suffered from one chronic disease, accounting for 47.8\%; most of the respondents were currently retired, accounting for $85.9 \%$.

Statistics of activity participation situation of the centres are shown in Table 2. The length of time for the elderly to use the community care centres for the majority was 3-5 years, accounting for $72.8 \%$; the motivation for the participation was mostly from the invitation by friends and relatives, accounting for $48.9 \%$; only $8.7 \%$ joined in the activities with family members living together; $94.6 \%$ of them had never discontinued the participation in center activities; it can be seen from the above findings that the participants had used the community care centres for long and continuously. 
Table 1: Social characteristics of subjects; $\mathrm{N}=92$.

\begin{tabular}{|c|c|c|c|}
\hline \multicolumn{2}{|c|}{ Variables } & \multirow{2}{*}{$\begin{array}{l}\mathbf{N} \\
40\end{array}$} & \multirow{2}{*}{$\begin{array}{c}\% \\
43.5\end{array}$} \\
\hline$C_{\text {a }}$ & Males & & \\
\hline पूता & Females & 52 & 56.5 \\
\hline \multirow{3}{*}{ Age } & $65 \sim 74$ years & 50 & 54.3 \\
\hline & $75 \sim 4$ years & 34 & 37 \\
\hline & $\geqq 85$ years & 8 & 8.7 \\
\hline \multirow{3}{*}{ Educational level } & Illiteracy & 20 & 21.7 \\
\hline & Complete primary school & 45 & 48.9 \\
\hline & Above secondary school & 27 & 29.4 \\
\hline \multirow{2}{*}{ Marital status } & Spouse & 50 & 54.3 \\
\hline & No spouse & 42 & 45.7 \\
\hline \multirow{3}{*}{ Living status } & Alone & 12 & 13.1 \\
\hline & Only with spouse & 20 & 21.7 \\
\hline & With family & 60 & 65.2 \\
\hline \multirow{2}{*}{ Religion } & No & 2 & 2.2 \\
\hline & Yes & 90 & 97.8 \\
\hline \multirow{4}{*}{ Chronic disease } & No & 27 & 29.4 \\
\hline & One & 44 & 47.8 \\
\hline & Two & 13 & 14.1 \\
\hline & $\geqq$ Three & 8 & 8.7 \\
\hline \multirow{2}{*}{ Currently working } & No & 79 & 85.9 \\
\hline & Yes & 13 & 14.1 \\
\hline
\end{tabular}

Table 2: Descriptive statistics of activity participation status of the centres; $N=92$.

\begin{tabular}{|c|c|c|c|}
\hline Variables & & $\mathbf{N}$ & $\%$ \\
\hline \multirow{3}{*}{ Duration time (year) } & $<1$ year & 5 & 5.5 \\
\hline & $1-<3$ years & 20 & 21.7 \\
\hline & 3-5 years & 67 & 72.8 \\
\hline \multirow{3}{*}{ Motivation for participation } & Friends and relatives & 45 & 48.9 \\
\hline & Neighborhood manager & 26 & 28.3 \\
\hline & Other & 21 & 22.8 \\
\hline \multirow{2}{*}{ Join with family } & No & 84 & 91.3 \\
\hline & Yes & 8 & 8.7 \\
\hline \multirow{2}{*}{$\begin{array}{l}\text { Interrupted the activity } \\
\text { participation }\end{array}$} & No & 87 & 94.6 \\
\hline & Yes & 5 & 5.4 \\
\hline \multirow{4}{*}{ Service content } & informal library services & 22 & 23.9 \\
\hline & catering services & 5 & 5.4 \\
\hline & health promotion & 40 & 43.5 \\
\hline & catering + health promotion & 25 & 27.2 \\
\hline \multirow{3}{*}{$\begin{array}{l}\text { Activity participation frequency } \\
\text { (week) catering services }\end{array}$} & No & 62 & 67.4 \\
\hline & 1 time & 24 & 26.1 \\
\hline & 2 times & 6 & 6.5 \\
\hline \multirow{4}{*}{ Health promotion } & No & 27 & 29.4 \\
\hline & 1 time & 46 & 50 \\
\hline & 2 times & 10 & 10.9 \\
\hline & 3-5 times & 9 & 9.8 \\
\hline \multirow{4}{*}{$\begin{array}{l}\text { Activity participation duration time } \\
\text { (year) catering services }\end{array}$} & No & 62 & 67.4 \\
\hline & $<1$ year & 3 & 3.3 \\
\hline & $1 \sim<3$ years & 6 & 6.5 \\
\hline & $3 \sim 5$ years & 21 & 22.8 \\
\hline
\end{tabular}




\begin{tabular}{|c|c|c|c|}
\hline \multirow{4}{*}{ Health promotion } & No & 27 & 29.4 \\
\cline { 2 - 4 } & $<1$ year & 5 & 5.4 \\
\cline { 2 - 4 } & $1 \sim<3$ years & 12 & 13 \\
\cline { 2 - 4 } & $3-5$ years & 48 & 52.2 \\
\hline \multirow{4}{*}{$\begin{array}{c}\text { Go to the center at non-activity time } \\
\text { Number of days }\end{array}$} & No & 20 & 21.7 \\
\cline { 2 - 4 } & Yes & 72 & 78.3 \\
\cline { 2 - 4 } & No & 20 & 21.7 \\
\cline { 2 - 4 } & $1-2$ days & 26 & 28.3 \\
\hline
\end{tabular}

The service the elderly mostly received was health promotion activities, accounting for $43.5 \%$, followed by both the food catering service and the health promotion activities, accounting for $27.2 \%$; $23.9 \%$ only used the space and equipment and did not use any of the official service items; among those who participated in health promotion activities, $52.2 \%$ had participated in the activities for 3-5 years, and $70.7 \%$ participated in the activity once or more often every week; for those who received food catering services, $22.8 \%$ had participated in it for 3-5 years, and $32.6 \%$ participated in the service once or more often every week. $78.3 \%$ would go to the center at non-activity time, and among them, $50 \%$ would go to the centres 3-5 days a week, and they went to the centres mainly for tea making, chatting or making use of the recreational facilities such as Karaoke and fitness equipment.

Table 3: Descriptive statistics of social interaction; $N=92$.

\begin{tabular}{|c|c|c|c|c|c|}
\hline \multirow{2}{*}{ Domain } & \multirow{2}{*}{ Item } & \multicolumn{2}{|c|}{ Family Relationship } & \multicolumn{2}{|c|}{ Neighbor Relationship } \\
\hline & & Mean & SD & Mean & SD \\
\hline \multirow{6}{*}{ Emotional } & 1. When I have to make a difficult decision, they will offer advice. & 3.88 & 0.73 & 3.42 & 0.9 \\
\hline & 2. They support and encourage me when I am in need. & 4.07 & 0.72 & 3.79 & 0.8 \\
\hline & 3. They ask me for my opinions or suggestion. & 3.84 & 0.91 & 3.6 & 0.97 \\
\hline & 4. We share our secrets or thoughts with each other. & 3.71 & 0.99 & 3.47 & 0.94 \\
\hline & 5. They treated me with respect. & 4.32 & 0.72 & 4.04 & 0.72 \\
\hline & Total & 3.96 & 0.63 & 3.66 & 0.66 \\
\hline \multirow{6}{*}{ Instrumental } & 6. When I need to go out, they help me with transportation. & 4.34 & 0.86 & 3.42 & 1.02 \\
\hline & $\begin{array}{l}\text { 7. They can accompany me in some unexpected situation or } \\
\text { emergencies. }\end{array}$ & 4.51 & 0.65 & 3.89 & 0.99 \\
\hline & $\begin{array}{l}\text { 8. My family can take care of me when I am sick. My neighbors can } \\
\text { visit me when I am sick. }\end{array}$ & 4.57 & 0.65 & 3.93 & 0.93 \\
\hline & $\begin{array}{l}\text { 9. When I need assistance in daily life, such as shopping, cooking, } \\
\text { making a phone call, etc., they can help me. }\end{array}$ & 4.56 & 0.68 & 3.95 & 0.98 \\
\hline & $\begin{array}{l}\text { 10. When I lack daily necessities, such as clothes, food, etc., they can } \\
\text { support me. }\end{array}$ & 4.45 & 0.73 & 3.7 & 0.9 \\
\hline & Total & 4.49 & 0.63 & 3.78 & 0.82 \\
\hline \multirow{5}{*}{ Informational } & 11. I If I need health related information, they will provide it for me. & 4.3 & 0.79 & 3.71 & 0.95 \\
\hline & $\begin{array}{l}\text { 12. I got some interesting information from them, such as shopping, } \\
\text { travel, eating, leisure activities etc. }\end{array}$ & 4.26 & 0.84 & 4.04 & 0.99 \\
\hline & $\begin{array}{l}\text { 13. My family and I share information about family activities. My } \\
\text { neighbors and I share information about community activities. }\end{array}$ & 4.29 & 0.73 & 4.35 & 0.86 \\
\hline & 14. We share information about community welfare with each other. & 4.39 & 0.72 & 4.32 & 0.85 \\
\hline & Total & 4.31 & 0.68 & 4.11 & 0.73 \\
\hline \multirow{7}{*}{ Interactive } & 15. We get along well. & 4.5 & 0.67 & 4.35 & 0.73 \\
\hline & $\begin{array}{l}\text { 16. When I walk around the community, I am acquainted with most } \\
\text { people in the neighborhood. }\end{array}$ & - & - & 4.4 & 0.79 \\
\hline & 17. We talk when meet each other. & 4.29 & 0.77 & 4.23 & 0.76 \\
\hline & 18. We help each other. & 4.51 & 0.67 & 4.26 & 0.73 \\
\hline & 19. I want to participate in their activities and help others. & 4.41 & 0.68 & 4.31 & 0.82 \\
\hline & Total & 4.42 & 0.6 & 4.31 & 0.64 \\
\hline & Overall scale & 4.29 & 0.56 & 3.96 & 0.63 \\
\hline
\end{tabular}


It can be learned from Table 3 that the mean of the overall scale of "family relationship" was 4.29 points, showing high level; for "neighbour relationship", the mean of the overall scale was 3.96 points, showing medium to high level. The overall mean in the emotional aspect was 3.96 points in "family relationship" and 3.66 points in "neighbour relationship"; that in the instrumental aspect was 4.49 points in "family relationship" and 3.78 points in "neighbour relationship"; that in the in informational aspect was 4.31 points in "family relationship" and 4.11 points in "neighbour relationship"; the overall mean in the interactive aspect was 4.42 points in "family relationship" and 4.31 in "neighbour relationship".

It can be learned from the mean of "family relationship" that instrumental aspect scored the highest while emotional aspect scored the lowest; for the mean of the "neighbour relationship", the highest score was in interactive aspect while the lowest in emotional aspect. For the elderly, the score of the "family relationship" in social interaction was higher than that of "neighbour relationship", and in all aspects of the family and neighbour relationships, emotional aspect all scored the lowest.

Take the demographic characteristics and the participation situation of the elderly in activities in the center as the independent variables and the four aspects of social interaction as the dependent variables to examine the difference by using independent sample $t$-test and one-way ANOVA. If the $t$ value or $F$ value reached significant level, Scheffe post hoc test was then conducted for the comparison of the difference between the groups. The statistical analysis and results are described as follows.

Table 4: Demographic characteristics and family relationship social interaction by t-test; $\mathrm{N}=92$.

\begin{tabular}{|c|c|c|c|c|c|c|c|c|c|c|c|c|c|}
\hline \multirow{2}{*}{ Variable } & \multirow{2}{*}{$\mathbf{N}$} & \multicolumn{3}{|c|}{ Emotional } & \multicolumn{3}{|c|}{ Instrumental } & \multicolumn{3}{|c|}{ Informational } & \multicolumn{3}{|c|}{ Interactive } \\
\hline & & Mean & SD & $\mathbf{t}$ & Mean & SD & $\mathbf{t}$ & Mean & SD & $\mathbf{t}$ & Mean & SD & $\mathbf{t}$ \\
\hline \multicolumn{14}{|c|}{ Work } \\
\hline No & 79 & 3.91 & 0.64 & \multirow{2}{*}{$2.02^{*}$} & 4.46 & 0.65 & \multirow{2}{*}{-0.85} & 4.3 & 0.7 & \multirow{2}{*}{-0.41} & 4.41 & 0.63 & \multirow{2}{*}{-0.57} \\
\hline Yes & 13 & 4.29 & 0.42 & & 4.63 & 0.46 & & 4.38 & 0.49 & & 4.51 & 0.43 & \\
\hline
\end{tabular}

It was shown in Table 4 that among the elders going to the centres, the "family relationship" of those without jobs reached significant level in "emotional aspect" $(t=-2.02, p=.046)$, and those with jobs had higher score $($ mean $=4.29)$ than those without jobs (mean=3.91). However, the variables of age, level of education, living status and chronic diseases had no significant difference in the "family relationship" and "neighbor relationship" of social interaction among the elders. Therefore, significant difference was reached in work status for the "emotional aspect" of the "family relationship" in social interaction.

Table 5: Participation status of the center and neighbour relationship social interaction by t-test; $N=92$.

\begin{tabular}{|c|c|c|c|c|c|c|c|c|c|c|c|c|c|}
\hline \multirow{2}{*}{ Variables } & \multirow{2}{*}{$\mathbf{N}$} & \multicolumn{3}{|c|}{ Emotional } & \multicolumn{3}{|c|}{ Instrumental } & \multicolumn{3}{|c|}{ Informational } & \multicolumn{3}{|c|}{ Interactive } \\
\hline & & Mean & SD & $\mathbf{t}$ & Mean & SD & $\mathbf{t}$ & Mean & SD & $\mathbf{t}$ & Mean & SD & $\mathbf{t}$ \\
\hline \multicolumn{14}{|c|}{ Go to center at other time } \\
\hline No & 20 & 3.71 & 0.44 & \multirow{2}{*}{0.39} & 3.7 & 0.8 & \multirow{2}{*}{-0.5} & 3.82 & 0.68 & \multirow{2}{*}{-1.72} & 4.11 & 0.41 & \multirow{2}{*}{$2.13^{*}$} \\
\hline Yes & 72 & 3.65 & 0.71 & & 3.8 & 0.82 & & 4.18 & 0.73 & & 4.37 & 0.68 & \\
\hline
\end{tabular}

Table 5 showed that the "neighbor relationship" reached significant level in "interactive aspect" ( $t=-2.13, p=.038)$, and the level of social interaction of those who went to the care centers at non-activity time (mean=4.37) was higher than those who did not go to the care centers at non-activity time (mean=4.11), but no significant level was reached in "emotional aspect", "instrumental aspect" and "informational aspect"; no significant level was reached in all aspects of "family relationship". Therefore, significant difference was reached in the "interactive aspect" of "neighbor relationship" in the social interaction among the elderly who would still go to the care centers at non-activity time.

Table 6-8 revealed that the service contents reached significant level in "emotional aspect" ( $\mathrm{F}=4.88, p=.003)$, "informational aspect" $(\mathrm{F}=5.04, p=.003)$ and "interactive aspect" ( $\mathrm{F}=7.11, p=.000)$ of the "family relationship", and it was found from the Scheffe post hoc comparison that the elderly who received both "food catering and health promotion services" and those who only received "health promotion services" had higher social interaction than those who only used "informal library services"; significant level was not reached in "instrumental aspect". The "interactive aspect" in "neighbor relationship" reached significant level $(\mathrm{F}=.50, p=.003)$, and it was found from the Scheffe post hoc comparison that the elderly who only received "health promotion services" had higher level of social interaction than those who only received "food catering services"; significant level was not reached in "emotional aspect", "instrumental aspect" and "informational aspect".

The frequency of center activities reached a significant level in the "emotional aspect" ( $\mathrm{F}=4.51, p=.005)$, "instrumental aspect" ( $\mathrm{F}=3.41, p=.021)$, "informational aspect" ( $\mathrm{F}=5.23, p=.002)$ and "interactive aspect" ( $\mathrm{F}=7.53, p=.000)$ of "family relationship" in health promotion, and it was found from the Scheffe post hoc comparison that the elderly who participated in activities once a week or more often had higher level of social interaction than those who did not. Significant level was reached in the "interactive aspect" of "neighbour relationship" ( $\mathrm{F}=3.05, p=.033)$, and it was found from the Scheffe post hoc comparison that the elderly who participated in activities 3-5 times a week had higher level of social interaction than those who did not; no significant level was reached in "emotional aspect", "instrumental aspect" and "informational aspect". Significant level was not reached in all aspects of the "family relationship" and "neighbour relationship" in food catering services. 


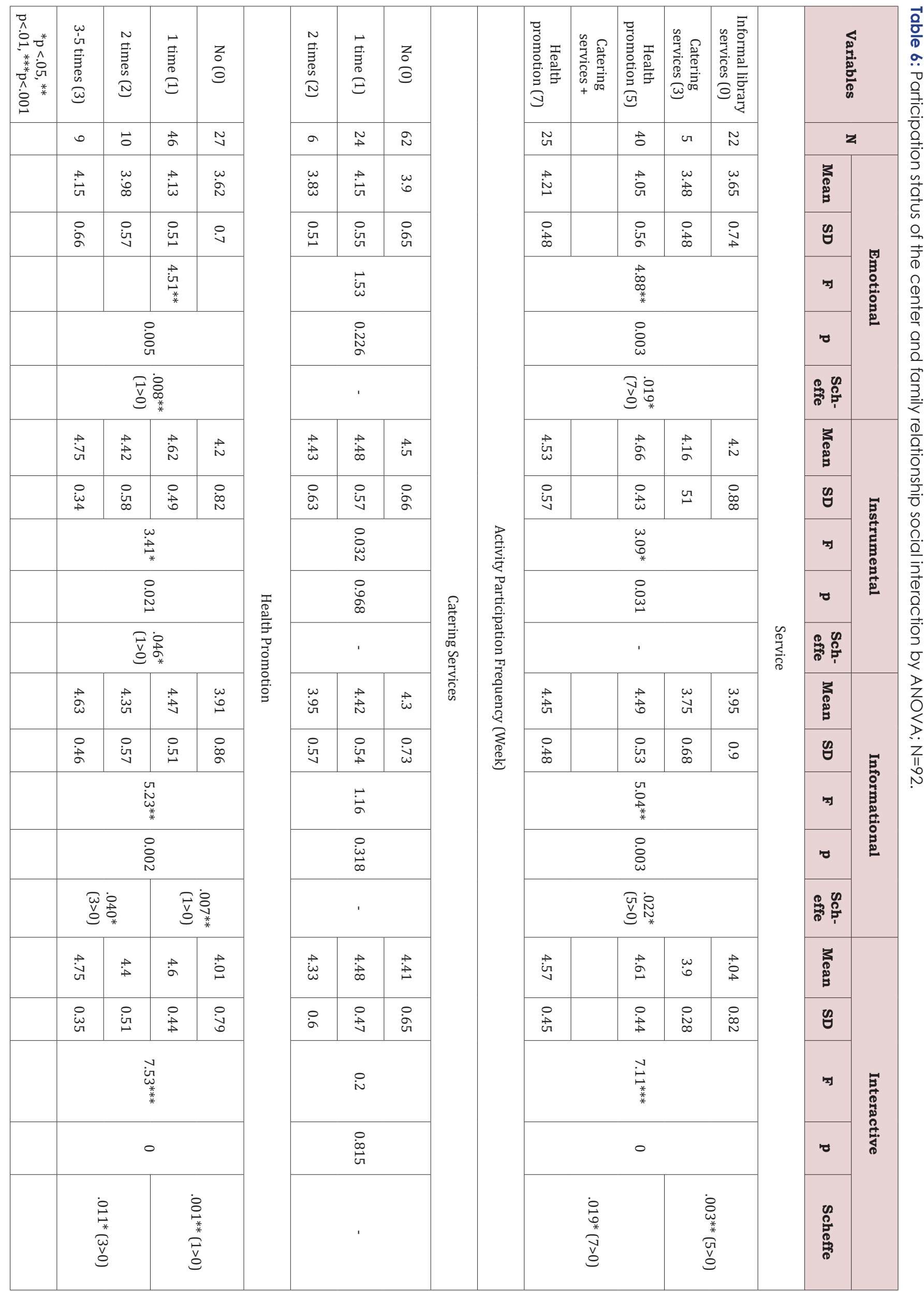




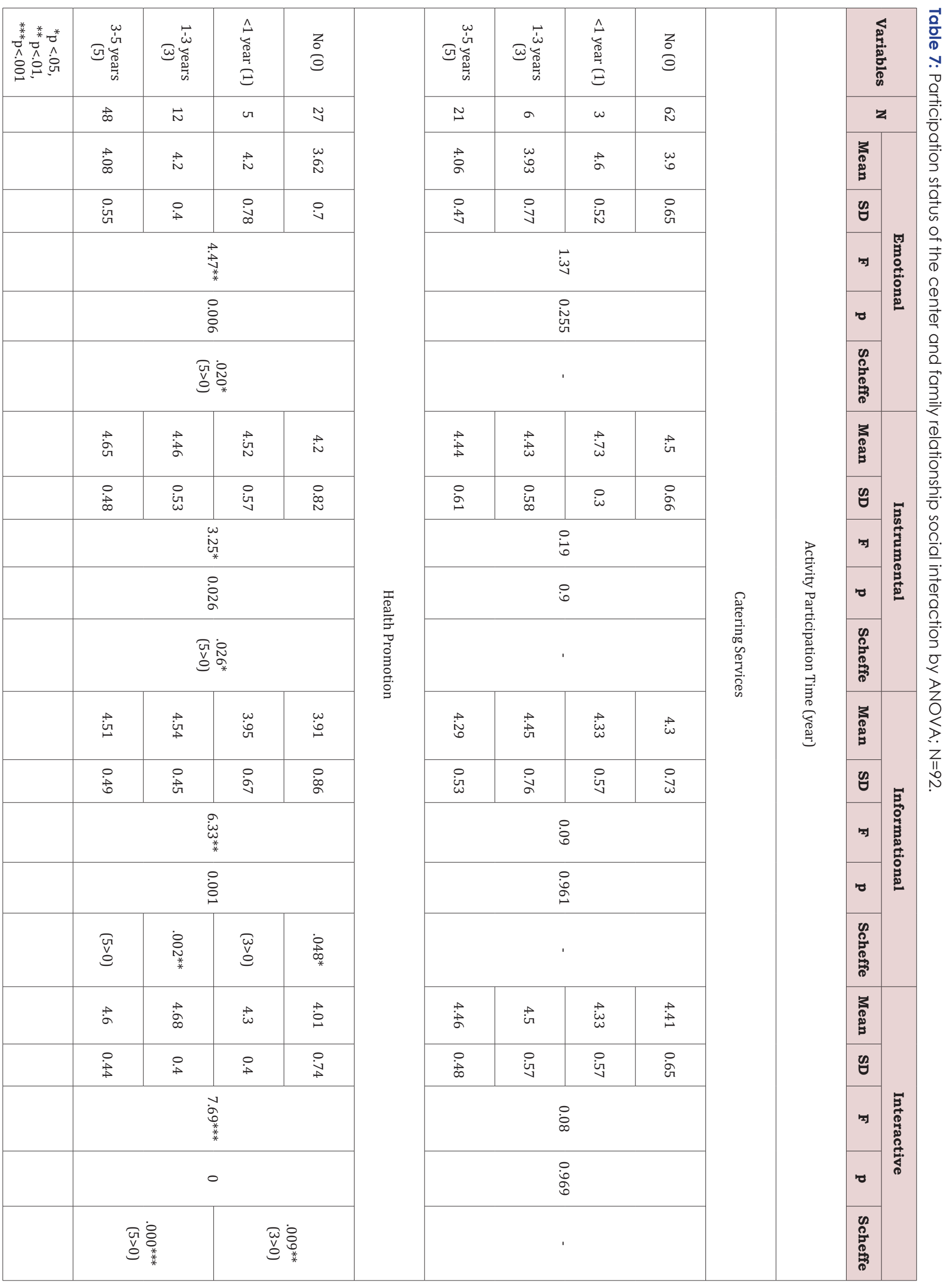




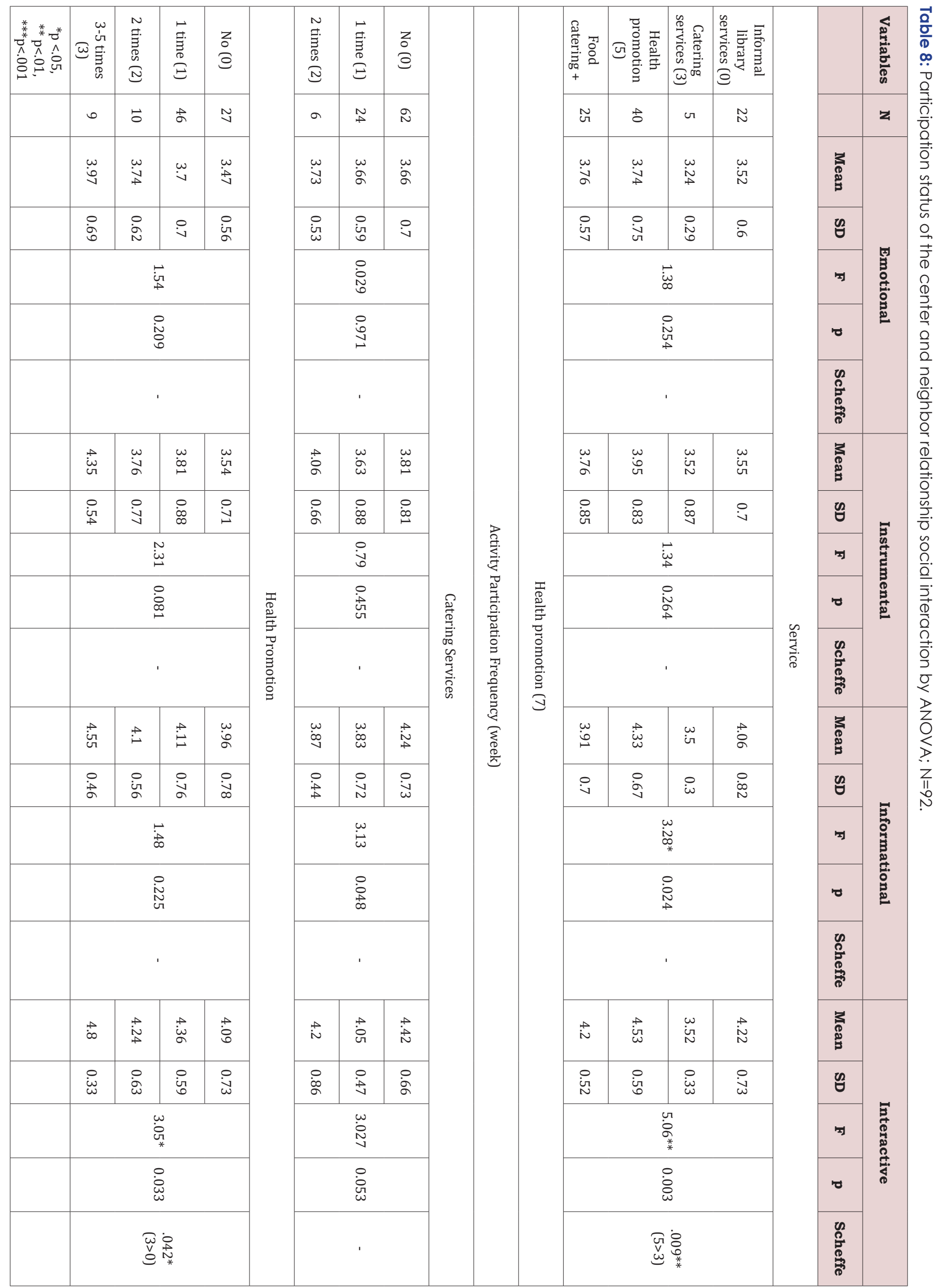


The length of time for the elderly to use the community care centres reached significant level in "emotional aspect" ( $F=4.47$, $\mathrm{p}=.006)$, "instrumental aspect" ( $\mathrm{F}=3.25, \mathrm{p}=.026)$, "informational aspect" ( $F=6.33, p=.001)$ and "interactive aspect" ( $F=7.69, p=.000)$ of "family relationship" in health promotion, and it was found from the Scheffe post hoc comparison that the elderly who had used the center for 3-5 years had higher level of social interaction in "emotional aspect" and "instrumental aspect" than those who did not use the center; those who had used the center for 1 year and above had higher social interaction in "informational aspect" and "interactive aspect" than those who did not use the centres. The aspects in "neighbour relationship" did not reach significant level. The aspects in "family relationship" and "neighbour relationship" under food catering service did not reach significant level.

There were no significant difference in the variables of length of time using the center, the motivation for participation, and the frequency of going to the center at non-activity time in social interaction of "family relationship" and "neighbour relationship". Therefore, the frequency and length of participation in health promotion activities had significant difference in social interaction of "family relationship" and "neighbour relationship" for the elderly.

\section{DISCUSSION}

The study showed that the elders using the centres were mostly females whose age was concentrated in the young old defined by WTO, the education level was generally lower than middle school, $50 \%$ of them had spouses, most of them lived with their family members, and most of them suffered from one chronic disease; the findings were similar to the demographic data distribution of the elderly in the community care centres in the studies conducted by Wang [17]; Wang [18]; Shih [19]; Ko [11]. The young old and those with fewer chronic diseases had better physical activities functions and were less likely to be restricted by physical strength, and therefore the level of their social interaction would be less influenced. Females were more willing to participate in social activities than males, which is different from traditional cognition. This may be because female elders are less reluctant to interact with others. In addition, the elders who continued to work would have higher level of emotional interaction with their family members, which was similar to the findings pointed out by $\mathrm{Wu}$ [1]; Wu [2]. The "work status" belonged to dynamic interaction in the basic characteristics of the elderly. Therefore, compared with other variables, the elders could interact with others through work, reaching social participation and continuing a certain life style as the activity and continuity theory advocated by sociologists, and these elders would have higher self-identity and social relations, and this shift of their life focus made it less likely for them to have conflicts with their family members. The provision of a convenient and diversified community care centres can help the elderly maintain or actively develop their social roles in their later life so that they can adapt to changes in life after retirement and to serve as a link between the elderly and their family members as well as their neighbours and thereby obtain self-affirmation and positive emotions that can enable them to retain the ability of independent living.

A majority of the elders had used the care centres for 3-5 years, which was probably because that there originally existed the village care centres in Tainan county before their transformation into the community care centres in 2005, and most elders used to participate in activities at the village care centers in early times. However, there were only 25 elders who had used the care center for less than 3 years, showing that there were not many newcomers after the implementation of the community care center programs, which may be because that the cost of the care centres were limited by the space and budgetary subsidies, which in turn affected the care centres to provide more active services to more elders in the community. The elders could use the community care centres for a long time and continued using them. In addition, they would also invite their friends in the community to participate in the activities, and most elders would participate in health promotion activities or more than 2 activities, and the more frequently as well as the longer they participated in the activities, the higher level of interaction they would have with their families and neighbours; the finding were similar to those in Shih's (2014) study on the length of time of the elderly participation in the community care centres and Wang's (2008) study on the service items and frequency for the elderly to use the community care centres; the same findings were found in the study conducted by Ko [11] that the elders using health promotion activities had better social functions; the findings were consistent to those in Lin's 2011 study that the more frequently the elders participated in activities, the more positive influence there was on their overall evaluation of social interaction, and consistent to those in Chai's 2007 study that the frequency of participation had an interference effect on the relationship of social support for the elderly. In Ko's 2014 study, the informal library services served the most people in terms of the frequency of usage of the community care centres, although it is different from the findings of this report that most people participated in health promotion activities, about $80 \%$ of the elders in Sinshih District would often go to the community care centres in their free time to make tea and chat with each other because these libraries in the community care centres were open 8 hours a day, 5 days a week, and the informal library services provided include blood pressure measurement, fitness equipment, newspapers and magazines, karaoke, and tea area, a space for them to interact with their neighbours aside from going there for activity participation. It was also found in this study that those elders who still went to the community care centres at non-activity time would have higher level of interaction with their neighbours, which was similar to those found in Seeman [20] study that the more frequent face-to-face interaction the elder had, the higher emotional and instrumental support they got [21-23].

\section{CONCLUSION}

It can be seen from the above findings that the establishment of the community care centres enabled the elderly whose radius of action was focused on the community to have closer interaction with their family members and neighbours, which could enhance their identity in their social circle, giving the elderly a sense of belonging. Diversified activities can encourage the elderly to communicate with their neighbours and share the results with their family members, and therefore, they were more likely to get psychological satisfaction. However, the personal traits of the elderly would affect their social participation abilities. Therefore, the community care centres can design various types of activities to address individual needs of different elderly people, and programs that can encourage male elders to participate in social activities more often should also be developed. Local cultural and community resources can also be combined to enrich the volume of services to increase the participation of the elderly. In addition, comprehensive equipment and facilities can be added to provide a recreational space for the elderly in the community to make use of in their daily life so as to increase the opportunities for social interaction among the elderly and achieve the effect of maintaining the physical, mental and social health of the elderly. 


\section{DISCLOSURE AND DECLARATION}

There is no conflict of interest in this research, and I have complied with Helsinki Ethical Declaration in the treatment of their sample.

\section{REFERENCES}

1. Wu IT (2010) A study of aging experiences and adaptations of older adults in hsinchu. Master Thesis, Department of Adult Education and Human Resource Development Hsuan Chuang University, Taiwan.

2. Wu PW (2011) A study of the relationships among Interpersonal Intimacy, Social Participation, and mental health in elders. Master Thesis, Department of Psychology and Counseling College of Education, National Taipei University of Education. Taiwan.

3. Rowe J, Kahn R (1997) Successful aging. The Gerontologist 37(4): 433440.

4. WHO (2002) Active ageing a policy framework?

5. Lewis KH, Gillman MW, Greaney ML, Puleo E, Bennett GG, et al. (2012) Relationships between Social Resources and Healthful Behaviors across the Age Spectrum. J Aging Res 2012.

6. Pieter-Paul V, Tampubolon G (2012) Individual social capital, neighbourhood deprivation, and self-rated health in England. Social Science \& Medicine 75(2): 349-357.

7. Steptoe A, Shankar A, Demakakos P, Wardle J (2013) Social isolation, oneliness, and all-cause mortality in older men and women. Proceedings of the National Academy of Sciences 110(15): 5797-5801.

8. Hsieh MO (2013) Exploring quality of life among the retired elderly from retirement planning, sociological theories of aging, self-perception of the elderly and the meaning of life. Soochow Journal of Social Work 25: 30-70.

9. (2019) Social and family affairs administration ministry of health and welfare.

10. Lee CW (2013) A study of policy evaluation of community care site: The case of Taichung city. Master Thesis, Department of Public Policy and Administration, College of Humanities, National Chi Nan University, Taiwan.

11. Ko HY (2014) Relationship of the performance of community care center and its accreditation outcome-an example of Tainan County. Master Thesis, Institute of Gerontology, National Cheng Kung University, Taiwan.
12. Cheng SF, Cheng CW, Ji M J, Lin SR, HOU WJ (2016) Analysis on elderly service users in community care bases in Taiwan. Journal of Gerontechnology and Service Management 4(2): 315-316.

13. Kraemer HC, Thiemann S (1987) How many subjects? Statistical power analysis in research. Newbury Park, California, USA.

14. Chen HC (2013) Social interaction as mediator between out-of-home trips and health among older adults. Master Thesis, Institue of Physical Education, Health and Leisure Studies, National Cheng Kung University, Taiwan.

15. Lin YY (2011) Influence of leisure activities and social interaction on psychological status of the elderly: A case of fenglin township, Hualien County. Master Thesis, Department of Somatics and Sport Leisure Industry, National Taitung University, Taiwan.

16. Chen YC (2011) An empirical study on health status, Health Promotion, social support, and life satisfaction: Example of senior citizens in Kinmen county. Master Thesis, Executive Master of Business Administration, National University of Kaohsiung, Taiwan.

17.Wang HL (2008) The relationship between community care section service and quality of life of elderly people -an example of Kaoshiung City. Master Thesis, Department of Social Policy and Social Work, National Chi Nan University, Taiwan.

18. Wang SF (2012) The study of the aged's social support and life quality: according to "community care station. Master Thesis, Graduate Institute of Health Care, MeiHo University, Taiwan.

19. Shih CJ (2014) To study and discuss the factors of influencing life satisfaction and self-perceived health of the participants in the community care station. Master Thesis, Department of Applied Sociology and Institute of Sociology, Nanhua University, Taiwan.

20. Seeman TE, Berkman LF (1988) Structural characteristics of social networks and their relationship with social support in the elderly: Who provides support. Social Science \& Medicine 26(7): 737-749.

21. Chai GC (2007) The relationship between social support, perceived health status, leisure participation and life effectiveness of the elder: The example of elderly college in taichung area. Master Thesis, Department of Leisure Management, Chaoyang University of Technology, Taiwan.

22. (2019) Social and family affairs administration ministry of health and welfare. Community Care Service Portal.

23. Wu SF (2015) The relationship between retirement and depression in community-dwelling older person. Master Thesis, Department of Health Care Administration, Chang Jung Christian University, Taiwan. 